\title{
SOME ASPECTS OF THE EXPERIMENTAL ASSESSMENT OF DYNAMIC BEHAVIOR OF THE RAILWAY TRACK
}

\author{
Vladimir Solonenko, Narzankul Mahmetova, Janat Musayev, Mikhail Kvashnin \\ Kazakh Academy of Transport and Communications Named after M. Tynyshpayev, Department of Transport Engineering \\ and Technologies, Almaty, Kazakhstan \\ e-mail:v.solonenko@mail.ru; mussaev75@yandex.kz; mussaev1975@mail.ru; kvashnin_mj55@mail.ru \\ Azamat Alpeisov, Algazy Zhauyt \\ Kazakh National Technical University Named after K.I. Satpayev, Department of Applied Mechanics and Basics of Machine \\ Design, Almaty, Kazakhstan \\ e-mail:ssitm@mail.ru; ali84jauit@mail.ru
}

\begin{abstract}
The paper suggests application of an experimental method for the assessment of the dynamic effect of a locomotive underframe on the railway track. The assessment is to be based on spectral analysis of the response of structural elements of the railway track undergoing a shock pulse. Application of digital measuring systems for monitoring of motion of the train is also proposed.
\end{abstract}

Keywords: railway track, dynamic effect, integrated monitoring, spectral analysis, railway track elements

\section{Introductions}

A railway track is a subsystem of the railway transport infrastructure, including track super structure, roadbed; drainage, anti-deformation, protective and strengthening structures of the roadbed located in the right-of-way, as well as other engineering structures (Kaewunruen and Remennikov, 2007). The state of the track depends on the continuity and safety of the rolling stock movement as well as the effective use of technical facilities of the railways (Knothe and Grassie, 1993; Liang and Zhu, 2001). Under conditions of constant exposure to natural and anthropogenic factors, the track takes heavy loads from the passing trains. In this case, all the track elements in terms of reliability, durability and stability must ensure a safe and smooth movement of trains with the greatest loads from sets of wheels of the rolling stock on rails and with maximum movement speeds, and have sufficient reserves (Smutny, 2004). During operation of the railway structures, it is necessary to consider their ability to maintain the initial parameters after exposure to natural and man-induced impacts. The nature of these effects is determined by the impact of various factors, including the level of vibrations occurring during rolling stock motion. Vibration actions have a significant impact on the railway track state (Wu and Thompson, 2004). The causes of their occurrence are as follows:

- Moving loads (quasi-static excitation), i.e. deflection of the track and supporting system along with movement of the train. On a fixed point on the rail-track, the fluctuating loads cause the occurrence of flexural waves both in the rails and in the surrounding soil. The mechanism of this excitation is not yet known in details (including the influence of boundary conditions, dissimilarity of the track and ground on wave propagation) (Abdelkrim et al., 2003). If a high-speed train is moving along the track laid on a soft ground, the speed of its movement can exceed the speed of propagation of the surface (Rayleigh) wave in the ground. This creates high level vibrations just like flight of a supersonic aircraft is 
accompanied by sonic boom. Above all, such vibration has an effect not only on the state of the track as a whole, but on its components individually (Alves Costa et al., 2010). To solve this problem, the ballast layer of the rail-track is placed on a compacted soil or concrete slabs with pile foundation, which reaches more dense soil layers (Berggren et al., 2010). If the rail-track is laid in a tunnel, its lining and arch invert provides a rigid base reducing the vibration level propagating in the surrounding soil.

- Roughness of the surface of wheels and rails. Random roughness in the area of the rail contact with the wheel causes excitation of the entire rolling stock-rail-track system (Bodare, 2009). Such roughness occurs primarily in the manufacturing process, so during inspection, it is necessary to control and test the state of the track and wheels. However, it cannot prevent the occurrence of roughness in the process of operation.

- Parametric excitation. If the rail support has a discrete structure of cross-sleepers, the elastic supports above the concrete basis (as opposed to the rails embedded in concrete) and the wheel while running on the rail "feel" the change in the support stiffness. Variable elastic forces create vibrations of the wheel and rail at a frequency that depends on the speed of the rolling stock and spatial discreteness of the support. Other discreteness (and excitation frequencies corresponding to it) is characterized by the distance between the wheelsets and bogies (Choi, 2013a,b). If the excitation frequencies coincide with the natural frequencies of the railway track, the vibrations of the track and surrounding soil can be quite considerable. The frequency of the impact $f_{k}[\mathrm{~Hz}]$, corresponding to the $n$-th characteristic distance $l_{v}[\mathrm{~m}]$ (see Fig. 1) is determined via the rolling stock speed $V[\mathrm{~m} / \mathrm{s}]$, according to the formula.

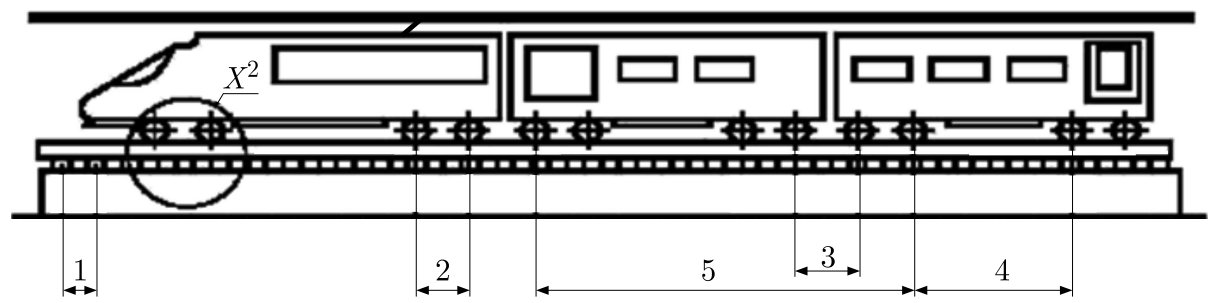

Fig. 1. Characteristic parameters of the vibration source; 1 - distance between supporting elements of the track, 2 - distance between wheelsets of the bogie carriage, 3 - distance between the adjacent bogie carriages of the adjacent railcars, 4 - distance between bogie carriages of one railcar, 5 - distance between railcars

- Wheel (rail) defects. In addition to the roughness on the surface of wheels and rails, there can be also observed rough defects occurring during rail-track operation. The major defects are associated with the presence of wheel flats and corrugations of the rails. Moreover, the wheels are subjected to such defects as out-of-roundness, out-of-balance and eccentricity (Choi et al., 2011a,b). In the course of time, the defects accumulate, especially if the track is not provided with a timely and proper technical care and maintenance.

- Discontinuities in the running surface of rails (in track switches, rail joints, etc.) causing the occurrence of bumps. If length of the joint or welded rails is equal to the distance between the carriage bogies, the vibration level may be increased significantly.

- Suspension of the rolling stock.

- Random or periodic changes in hardness of the rail running surface due to defects in workmanship or (more likely) resulting from the ageing process of the rail-track.

- Loads in the transverse direction, particularly during motion of the rolling stock along a curved track of small radius, or when passing turnouts. 
- Changing the mode of motion. Acceleration or deceleration of the rolling stock is accompanied by the occurrence of variable forces and oscillations.

- External factors. For example, temperature and humidity of the rail head influence its wear and tear and, consequently, result in vibration occurrence (Kaewunruen and Remennikov, 2006a,b, 2007a,b).

The vibration level due to the above reasons depends on the input impedances (resistance of the medium to spread mechanical vibrations) of the rail head and wheel rim in the area of their contact. The value of the input impedance of the rail head is determined by the track superstructure, its basis as well as characteristics of the surrounding soil ( $\mathrm{Li}$ et al., 2009; Li and Berggren, 2010).

\section{Materials and methods}

The wheel output impedance essentially depends on the unsprung mass of the locomotive underframe. However, total mass of the locomotive underframe together with the load is also very important for the rigid suspension (due to structural features of the damper and its behavior at high frequencies).

Given the above, to increase the level of safety of railway operation, it is necessary to apply progressive methods of diagnostics and monitoring aimed at the assessment of the vibration level occurring during operation and of the current status of all elements of the railway track. The need and urgency of implementing innovative systems and means of diagnostics and monitoring of the railway facility are reflected in Programs for the development of railway system until 2020 in the Republic of Kazakhstan.

Based on the study of dynamic processes occurring in strategic facilities (Clark, 2004), in particular in the railway track superstructure, it is suggested to carry out a comprehensive monitoring of the railway track system.

The monitoring system allows establishing a permanent instrumental control over the railway track state for a long period. In addition, it is possible to carry out an objective assessment of the impact of structural features of the track elements (rails, fasteners, cross-sleepers, etc.) on the level of vibrations occurring during notion of the rolling stock and take the best optimum decisions in the design of new and improvement of the existing track systems (Hall, 2002). The monitoring system includes standards (requirements for the arrangement and maintenance of the track superstructure by taking into account the operating conditions), controlled parameters, means of monitoring and measurement modes, assessment of the maximum permissible thresholds and tolerances.

The monitoring system has been developed using a mobile vibration-measuring equipment. The system consists of vibration sensors MV-25D-B which convert mechanical vibrations into electric signal. Transformation of an analog signal into a digital form is carried out within the electronic unit of the analog-to-digital converter (ADC manufactured by "L-CARD" Co., model E-14-440). Collection of digital data from ADC and common measurements control is implemented by means of a special software for PC. A general view to the mobile vibrationmeasuring system is shown in Fig. 2. All the measurement tools included in the mobile vibrationmeasuring facility are certified and calibrated. The operation of the system is powered by a rechargeable battery (Hamet, 1999).

The following may be referred to the main advantages of the mobile vibration-measuring system:

(i) the modular principle of the system configuration with universal power supply;

(ii) application of vibration sensors with high sensitivity in a wide range of frequencies and impact amplitudes; 


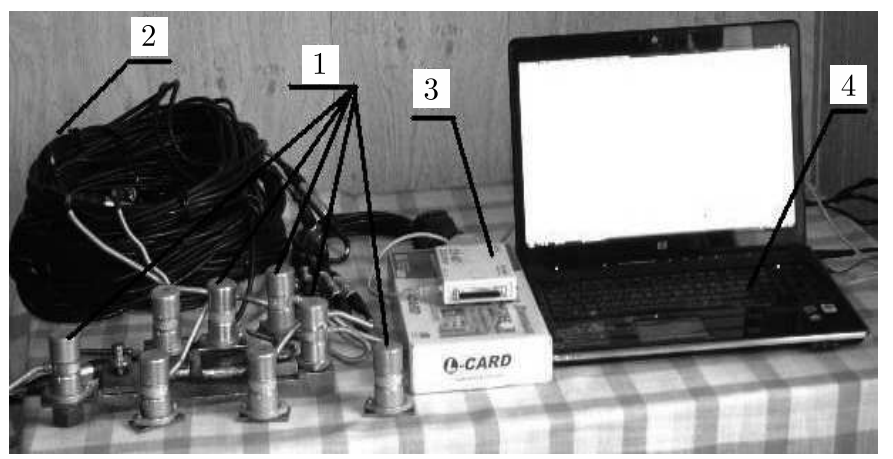

Fig. 2. General view of the mobile vibration-measuring system; 1 - vibration sensors, 2 - patch cable, 3 - multichannel ADC, 4 - laptop

(iii) application of multichannel ADC providing transfer of digitized data with high pin-point accuracy to the parallel port of a personal computer;

(iv) data acquisition in a digital format with possibility of software processing of the acquired information, its storage and systematization for the purpose of correlation detection;

(v) high reliability and working capacity in a wide range of climatic conditions;

(vi) insignificant dimensions and mass of all components.

Processing of the signals registered by vibration sensors is carried out by means of a special software installed on a laptop. Direct recording of a signal is carried out by means of application of the software LGraph2. This software provides possibility for setting the signals recording parameters and signals visualization in real time. Functionally, LGraph2 software represents a digital oscilloscope. Then the results of measurements are stored on the hard disk drive of the computer in "txt" format. As a result of primary data translation in the text format, they represent a dependence of electrical voltage generated by the sensor on time. The vibration sensors are calibrated before determination of the transformation coefficients.

There is a relationship for $U_{n}$ depending on time $t_{n}, n=0, \ldots, N-1$, where $N$ is the number of counts, $T=t_{N-1}$ is the time length of signal realization. The actual vibration speed is calculated per voltage values

$$
v_{n}=\frac{U_{n}}{K_{n}}
$$

where $K_{n}$ is the sensor transformation coefficient.

The vibration sensors are preliminarily calibrated on vibration table ESE 201 to determine the transformation coefficients. The transition from the time to frequency domain is carried out using the direct Fourier transformation

$$
V_{k}=\sum_{n=0}^{N-1} v_{n} \exp \left(\frac{-2 \pi \mathrm{i} k_{n}}{N}\right)
$$

In order to obtain the amplitude-time dependence of the vibrational displacement (oscillograms), it is necessary to integrate the function $v_{n}$ (Fig. 3). For this, let us use the property of the direct Fourier transformation (DFT)

$$
\widehat{F}^{\prime}=2 \pi \mathrm{i} f \widehat{F}
$$

where $\widehat{F}$ is DFT of the function $F$ with respect to $V_{k}$ (Fig. 4). Then, by the inverse of Fourier transformation (IFT), we obtain (Fig. 5)

$$
S_{k}=\frac{V_{k}}{2 \pi \mathrm{i} f_{k}+\pi V_{0} \Delta f}
$$




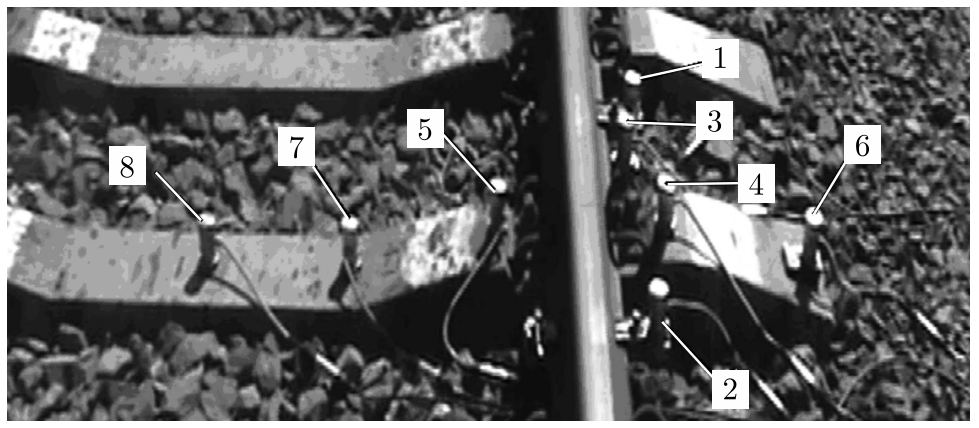

Fig. 3. Amplitude-time dependence of vibrational speed obtained on the rail base during passage of locomotive VL80

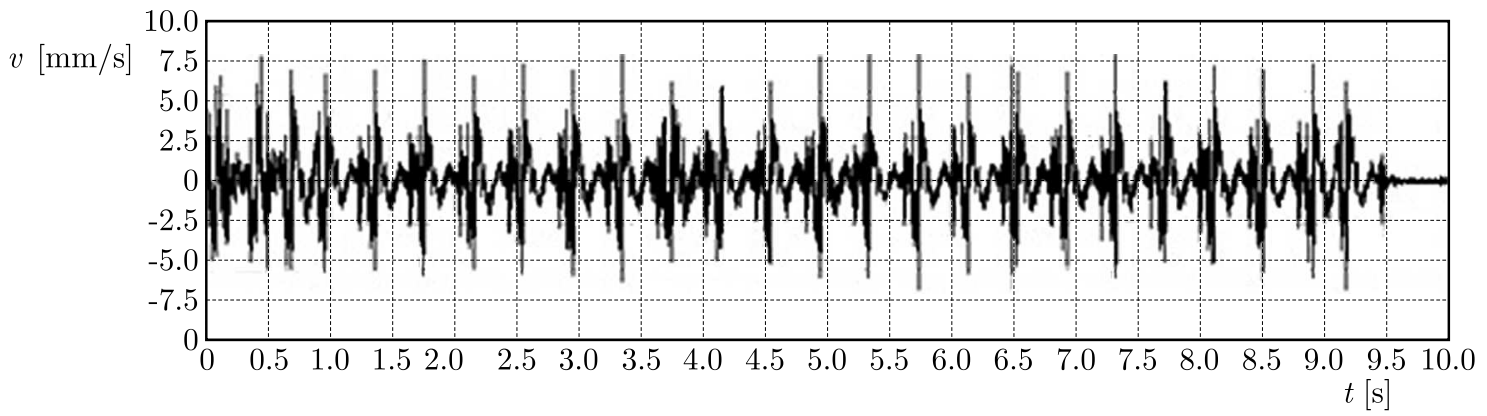

Fig. 4. Spectrum of vibrational speed obtained on the rail base during passage of locomotive VL80

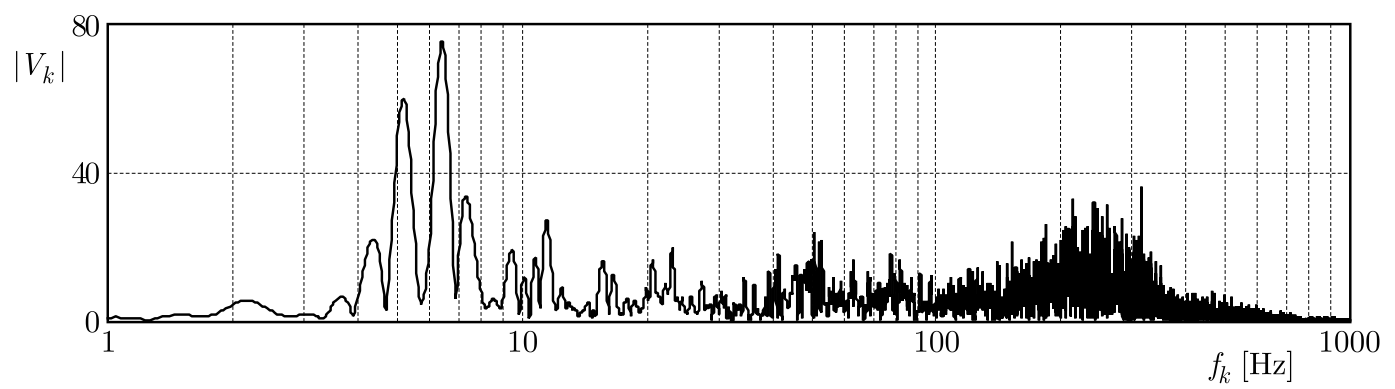

Fig. 5. Spectrum of displacement obtained on the rail base during passage of locomotive VL80

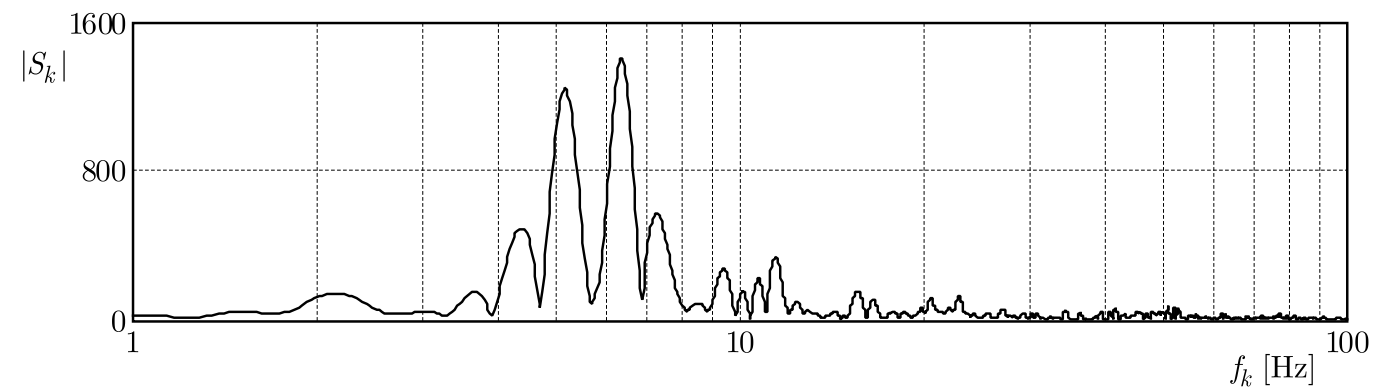

Fig. 6. Amplitude-time dependence of the vibrational displacement obtained on the rail base during passage of locomotive VL80

where $\Delta f=1 / T$ (signal sampling by frequency), $f_{k}=\Delta f_{k}$. Figure 6 shows the oscillogram spectrum obtained on the rail base during passage of locomotive VL80.

Let us make IFT to return to the time domain

$$
S_{n}=\frac{1}{N} \sum_{k=0}^{N-1} S_{k} \exp \left(\frac{2 \pi \mathrm{i} k_{n}}{N}\right)
$$




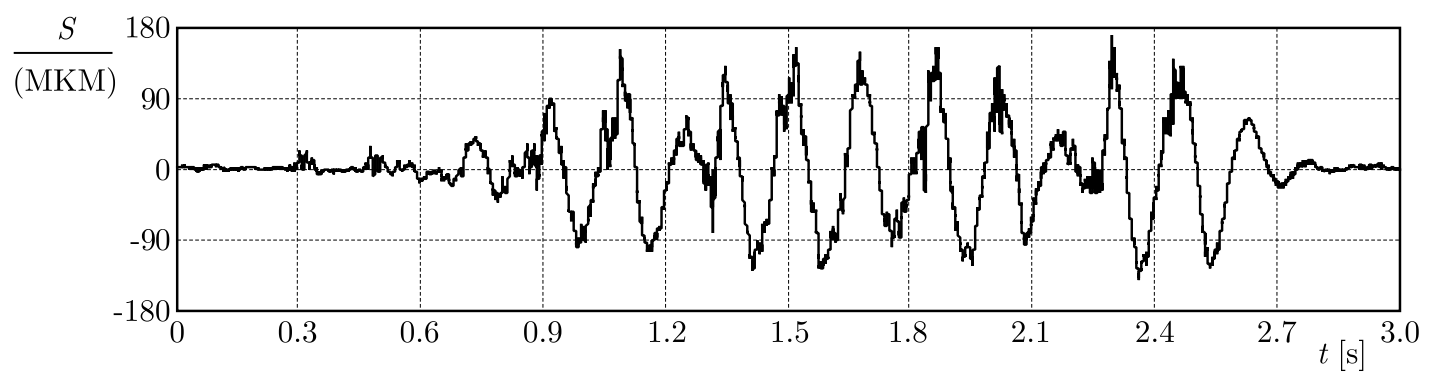

Fig. 7. Spectrum of vibrational acceleration obtained on the rail base during passage of locomotive VL80

Hence, we obtain the amplitude-time dependence of the vibrational displacement on time (Fig. 7). For obtaining of amplitude-time dependence of vibrational accelerations (accelerograms), it is necessary to differentiate $v_{n}$ and consider elimniation of distortion of the sensor transformation coefficient in the frequency domain over $1000 \mathrm{~Hz}$. For differentiation, let us again make use of DFT property represented by expression (2.3), and use Butterworth filter for the elimination of distortion in the low frequencies domain

$$
A_{k}=V_{k} H_{k}\left(2 \pi \mathrm{i} f_{k}\right)
$$

where $H_{k}$ is Butterworth filter

$$
H_{k}=\frac{1}{\sqrt{1+\left(\frac{f_{k}}{f_{B}}\right)^{2 p}}} \frac{1}{\sqrt{1+\left(\frac{f_{H}}{f_{k}+1}\right)^{2 p}}}
$$

where $\left(f_{H}, f_{B}\right)$ is the range of frequencies passing through the filter; $p$ is the filter order. Butterworth filter characteristics are given in Fig. 8.

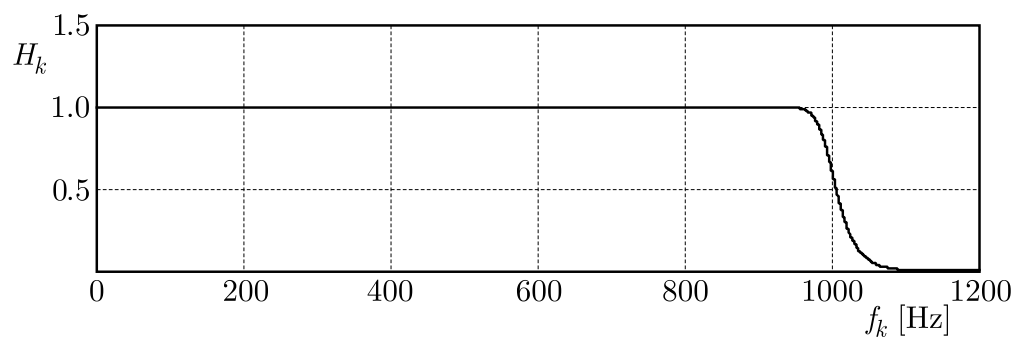

Fig. 8. Butterworth filter characteristics in the low frequency domain at $f_{H}=0.1 \mathrm{~Hz}, f_{B}=1000 \mathrm{~Hz}$,

$$
p=50
$$

For the obtained amplitude $A_{k}$ (Fig. 7) let us make IFT. As a result, Eq. (2.7), we obtain the amplitude-time dependence of vibrational accelerations filtered in the low frequency domain in the following form

$$
a_{n}=\frac{1}{N} \sum_{k=0}^{N-1} A_{k} \exp \left(\frac{2 \pi \mathrm{i} k_{n}}{N}\right)
$$

For the assessment of data acquired during diagnostics and monitoring, the author of this paper has developed a package of application software for data processing and visualization based on Mathsoft Engineering \& Education Inc. "MATHCAD" products.

The procedure is developed for diagnostics of the track superstructure and then given are the results of its testing and adaptation to track sections with intermediate rail fastenings FOSSLOH, ZHBR-65SHD, ZHBR-65, KZF-07. 
The diagnostic technique is based on spectrum analysis of the track superstructure elements to the impact force. Excitation of free vibrations is carried out by a mechanical shock to the rail using a hammer. The use of rubber in the impact device is explained by impermissibility of the rail running surface damage (Kumaran et al., 2003).

The modulus of spectrum density of the response to the impact force is determined by

$$
|N(f)|=|S(f)||M(f)|
$$

where $|S(f)|$ is the modulus of spectrum of the impact force impulse $F(t),|M(f)|$ is the modulus of the amplitude-frequency characteristic of the track superstructure element under investigation.

During selection of the optimal parameter of the impact system, the following function is taken as the impact force impulse according to Hertz theory

$$
F(t)= \begin{cases}S_{0} \sin \frac{\pi t}{\tau} ; & \text { at } \quad 0 \leqslant t \leqslant \tau \\ 0 & \text { at } \quad t>\tau\end{cases}
$$

The modulus of spectrum density has the following form

$$
|S(f)|=\frac{2 S_{0} \tau}{\pi} \frac{\cos (\pi f \tau)}{1-(2 \pi f \tau)^{2}}
$$

where $S_{0}$ is the initial amplitude of vibrations of the track superstructure under the impact force (2.10), $\tau$ is the impulse length of collision of the impact system with the object, which in the first approximation is determined according to Hertz impact theory, i.e.:

$$
\tau=\frac{4.531}{\sqrt[5]{V_{0}}}\left(\frac{M\left(\frac{1-\mu_{1}^{2}}{E_{1}}+\frac{1-\mu_{2}^{2}}{E_{2}}\right)}{\pi \sqrt{R}}\right)^{\frac{2}{5}}
$$

where $E_{1}, E_{2}$ and $\mu_{1}, \mu_{2}$ are Young's moduli and Poisson's ratios of the hammer and rail steel material, respectively, $R$ is radius of the contact surface of the impact system, $V_{0}$ is linear velocity of the hammer, $M$ is reduced mass of the colliding bodies equal to

$$
M=\frac{m_{1} m_{2}}{m_{1}+m_{2}}
$$

where $m_{1}$ and $m_{2}$ are masses of the hammer and railway track structure, respectively.

In addition to the optimal choice of value $\tau$, the external energy delivered to the monitored object must be sufficient for excitation of normal bending vibrations in the track superstructure on the fundamental mode. The initial amplitude of these vibrations $S_{0}$ must be such as to give possibility to carry out qualitative spectrum analysis of recordable responses of the impact force $\left(S_{0}>10 \zeta\right)$ at a prescribed sensitivity of the receiving vibratory sensor $\zeta$. The initial amplitude of vibrations is determined by the formula

$$
S_{0}=\frac{F}{2 \pi m f_{0}}
$$

where $F$ is the initial force impulse, $f_{0}$ is the frequency of the first bending mode of the railway track, $m=m_{1}+m_{2}$.

The sensors layout depends on the priority task of research and may vary during diagnostics in very wide ranges. Figure 9 gives an example of the sensors positioning during diagnostics of the track superstructure. 


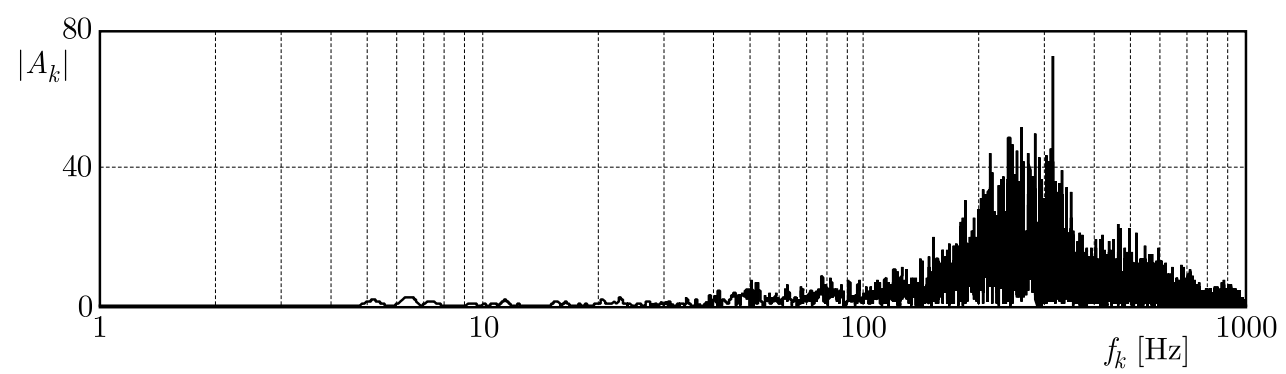

Fig. 9. General view of the sensors positioning during diagnostic of the track superstructure; 1,2 on the rail base, 3 on resilient clamp, 4 on cross-sleeper outside the rail, 5 on cross-sleeper inside the rail,

6 at cross-sleeper end, 7, 8 in center of the cross-sleeper

The following parameters are measured and analyzed during execution of diagnostics:

(i) frequencies corresponding to the modes of bending vibrations of the track superstructure $f_{i}$ (determined by spectra of responses obtained on different elements of the railway track);

(ii) logarithmic decrement to be determined on the basis of connection between the logarithmic decrement and width of the spectrum line

$$
d_{i}=\pi \frac{\Delta f_{i}}{f_{i}}
$$

where $d_{i}, \Delta f_{i}, f_{i}$ is the logarithmic decrement, width of the spectrum line, frequency of vibration modes of interest;

(iii) dynamic response factor $\beta_{i}$ is determined on the basis of the formula

$$
\beta_{i}=\frac{1}{\sqrt{\left(1-\frac{f_{v}^{2}}{f_{i}^{2}}\right)^{2}+\left(\frac{d_{i}}{\pi} \frac{f_{v}}{f_{i}}\right)^{2}}}
$$

where $f_{v}$ is the impact frequency;

(iv) $Q$ factor of the track superstructure on the vibration modes of interest is determined by the formula

$$
Q_{i}=\frac{\pi}{d_{i}}
$$

(v) speed of the rolling stock at which resonance phenomena occur, and which are determined based on the dependence of the impact frequency $f_{v}$ on the rolling stock speed $v$ and the parameters of vibration excitation $l_{v}$

$$
f_{v}=\frac{V}{l_{v}}
$$

\section{Experimental results and discussion}

In the paper, the topical issues of an experimental method for the assessment of dynamic impact of the locomotive body on the track is studied. The proposed method is based on spectral analysis of the railway track structural element responses to the impact impulse and monitoring of train motion with the use of digital measuring equipment.

To increase the level of safety of railway operation, the authors elaborated progressive methods of diagnostics and monitoring and introduced special engineering and technical measures 
to examine the impact of vibrations occurring during motion of the train on the current state of all railway track elements.

Figure 7 presents a structural diagram of data visualization of the railway track monitoring and the processing program.

The monitoring of trains movement along the studied track structure has been conducted for 6-15 days (depending on the loading level). It included the following ((Liang and Zhu, 2001):

- recording of dynamic processes in the railway track elements at different characters of the rolling load;

- determination of contact conditions between the track superstructure elements (rail-rail fastening, rail fastening-cross sleeper, cross sleeper-ballast section) using the vibroacoustic method (Fig. 10);

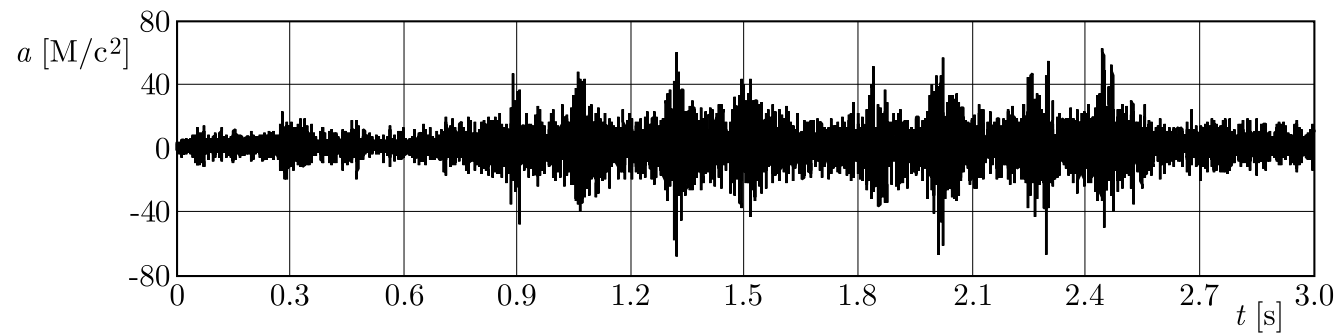

Fig. 10. Amplitude-time dependence of vibrational acceleration obtained on the rail base during during passage of locomotive VL80

- determination of normal (resonance) frequencies and damping properties of elements of the railway track (Fig. 11);
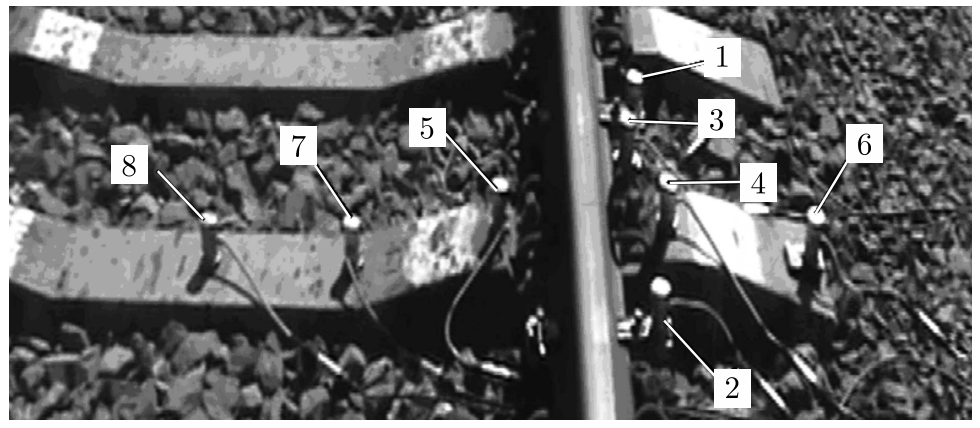

Fig. 11. Diagrams of the spectral density of vibration acceleration of free vibrations of the reinforced concrete cross-sleeper center: curve 1 - good contact of the cross-sleeper with the crushed stone underlayer, 2 - poor contact of the cross-sleeper with the crushed stone underlayer, 3 - the absence of contact of the cross-sleeper with the crushed stone underlayer

- forecasting of the rolling stock speed at which resonance phenomena occurred (Fig. 12);

- determination of impact conditions of the locomotive underframe on the track (Figs. 13 and 14).

\section{Conclusions}

Conducting a complex monitoring of the railway track allows one to carry out an objective assessment of the condition of track elements (different types of rail fastenings Table 1, various ballast fineness) on the level of vibrations occurring during motion of the rolling stock. It enables 


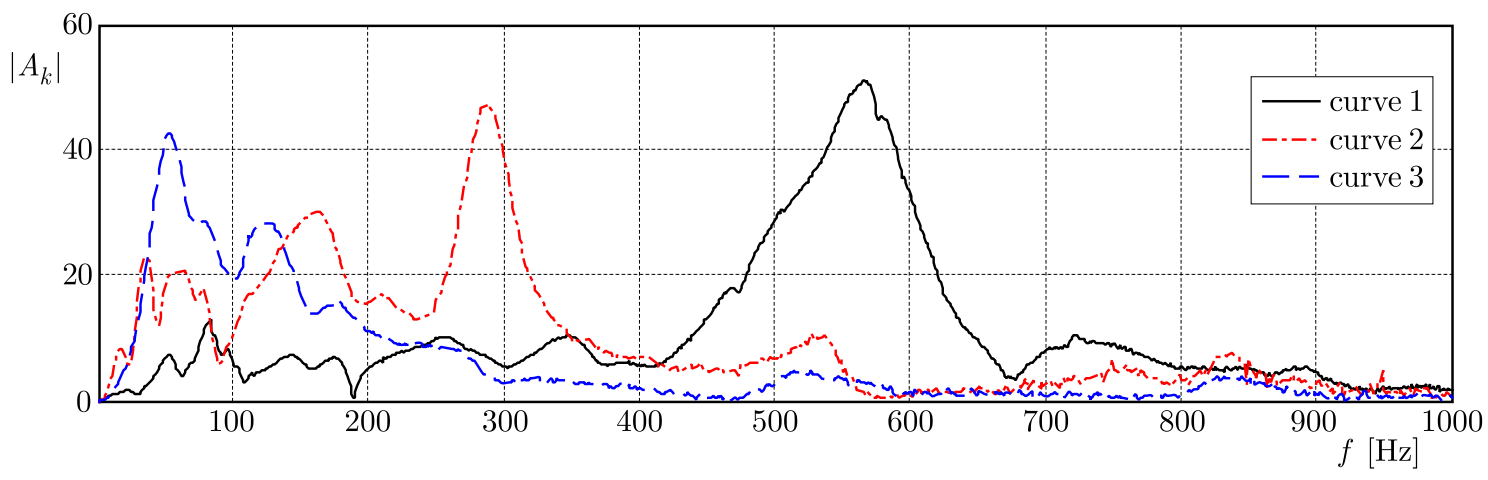

Fig. 12. Diagrams of the spectral density of vibration acceleration of free vibrations for different designs of the track superstructure: curve 1 - fastening of FOSSLOH type, 2 - fastening of KZF-07 type, 3 - fastening of ZHBR-65SHD type

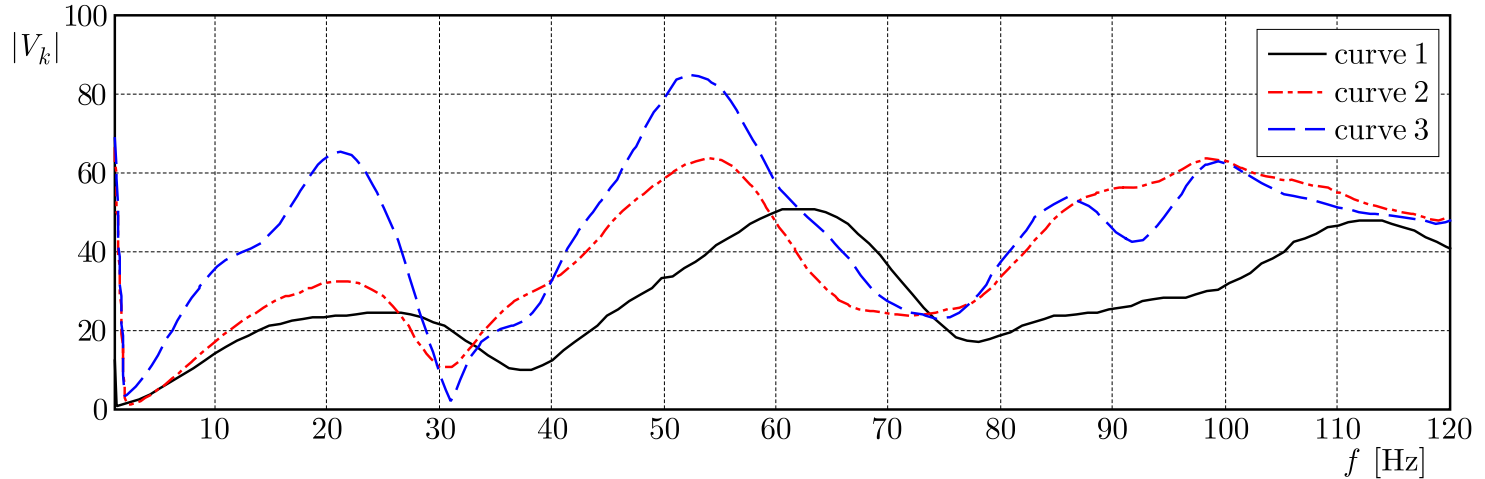

Fig. 13. Dependence of the dynamic response factor on speed of motion of the rolling stock for different solutions of the track superstructure: curve 1 - fastening of FOSSLOH type, 2 - fastening of KZF-07 type, 3 - fastening of ZHBR-65SHD type

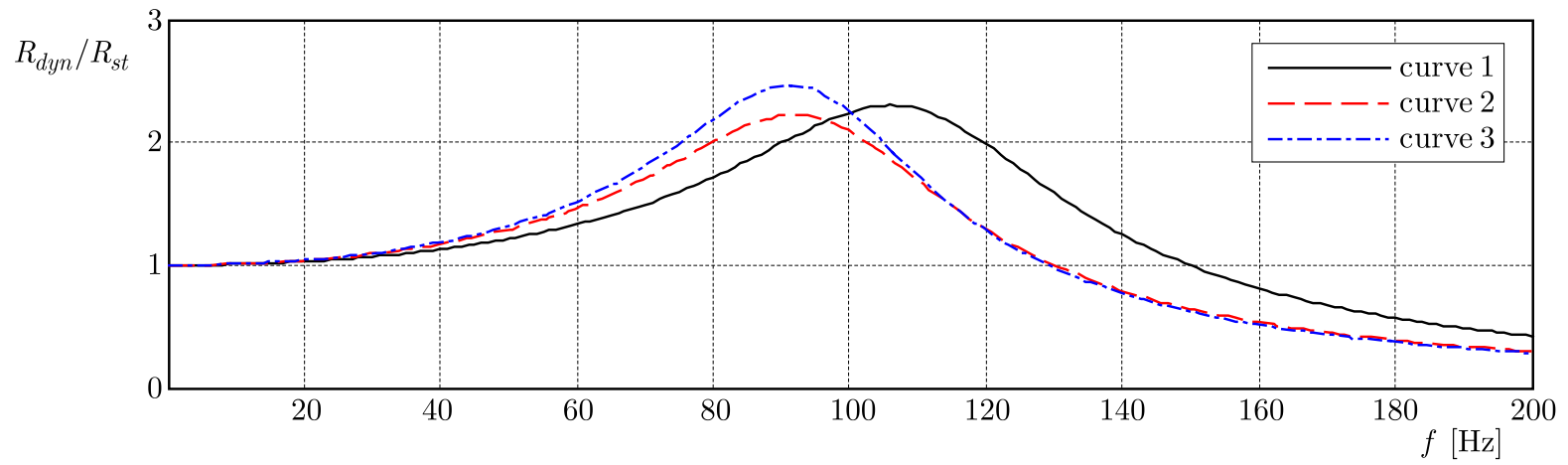

Fig. 14. Correlation of the rail base dynamic to the static force ratioo on electric with velocity of locomotive VL-80

making the most optimum decisions for the design of new tracks and renovation of the existing facilities. In addition, regular monitoring allows increasing the level of safety of the railway track and its operational lifetime as well as reducing the costs of current maintenance. The further direction of research should provide the development of complex systems for monitoring of railway tracks with the use of vibration-measuring equipment for the most objective assessment of their state. 
Table 1. Results of track superstructure diagnostics with various types of intermediate rail fastenings

\begin{tabular}{|l|c|c|c|c|c|c|c|}
\hline Type of fastening & $f_{1}[\mathrm{~Hz}]$ & $f_{2}[\mathrm{~Hz}]$ & $d_{1}$ & $d_{2}$ & $Q_{1}$ & $Q_{2}$ & $V_{2}[\mathrm{~km} / \mathrm{h}]$ \\
\hline \hline FOSSLOH & 22 & 62 & 3.6 & 1.4 & 1.06 & 2.3 & 106 \\
\hline KZF-07 & 21 & 54 & 2.84 & 1.45 & 1.24 & 2.23 & 92 \\
\hline ZHBR-65SHD & 20 & 53 & 2.9 & 1.3 & 1.22 & 2.47 & 91 \\
\hline ZHBR-65 & 14 & 33 & 3.3 & 1.52 & 1.18 & 2.13 & 56 \\
\hline
\end{tabular}

\section{References}

1. Abdelkrim M., Bonnet G., Buhan P., 2003, A computational procedure for predicting the long term residual settlement of a platform induced by repeated traffic loading, Computers and Geotechnics, 30, 463-476

2. Alves Costa P., Calçada R., Cardoso A.S., Bodare A., 2010, Influence of soil non-linearity on the dynamic response of high-speed railway track, Soil Dynamics and Earthquake Engineering, 30, 4, 221-235

3. Bergaren E.G., Kaynia A.M., Dehlbom B., 2010, Identification of substructure properties of railway tracks by dynamic stiffness measurements and simulations, Journal of Sound and Vibration, 329, 3999-4016

4. Bodare A., 2009, Evaluation of track stiffness with a vibrator for prediction of train-induced displacement on railway embankments, Soil Dynamics and Earthquake Engineering, 29, 8, 1187$-1197$

5. Chоі J.Y., 2013a, Influence of track support stiffness of ballasted track on dynamic wheel-rail forces, Journal of Transportation Engineering, 139, 709-718

6. Сног J.Y., 2013b, Prediction of displacement induced by tilting trains running on ballasted tracks through measurement of track impact factors, Engineering Failure Analysis, 31, 360-374

7. Choi J.Y., LeE D.W., PARK Y.G., 2011a, A study on the evaluation of track support stiffness on the various track type in urban transit, Journal of the Korean Society for Railway, 14, 3, 262-270

8. Choi J.Y., PARK Y.G., Lee S.M., 2011b, The evaluation of track impact factor on the various track type in urban transit, Journal of the Korean Society for Railway, 14, 3, 248-255

9. Clark R., 2004, Rail flaw detection: overview and needs for future developments, NDT\&E International, 37, 2, 111-118

10. HALL L., 2002, Simulations and analyses of train-induced ground vibrations in nite element models, Soil Dynamics and Earthquake Engineering, 23, 403-413

11. Hamet J.F., 1999, Railway noise: use of the Timoshenko model in rail vibration studies, Acustica, $\mathbf{8 5}, 1-12$

12. Kaewunruen S., Remennikov A., 2006a, Non-destructive testing (NDT): a tool for dynamic health monitoring of railway track structures, Materials Australia, 39, 6, 14-16

13. Kaewunruen S., Remennikov A., 2006b, Sensitivity analysis of free vibration characteristics of an in-situ railway concrete sleeper to variations of rail pad parameters, Journal of Sound and Vibration, 298, 1/2, 453-461

14. Kaewunruen S., Remennikov A., 2007a, Effect of improper ballast tamping packing on dynamic behaviors of on-track railway concrete sleeper, International Journal of Structural Stability and Dynamics, 7, 1, 167-177

15. Kaewunruen S., Remennikov A.M., 2007b, Field trials for dynamic characteristics of railway track and its components using impact excitation technique, NDT\&E International, 40, 7, 510-519

16. Knothe K., Grassie S.L., 1993, Modelling of railway track and vehicle/track interaction at high frequencies, Vehicle System Dynamics, 22, 3/4, 209-262 
17. Kumaran G., Menon D., Krishman Nair K., 2003, Dynamic studies of rail track sleepers in a track structure system, Journal of Sound and Vibration, 268, 485-501

18. Li M.X.D., Bergaren E.G., 2010, A study of the effect of global track stiffness and its variations on track performance: simulation and measurement, Journal of Rail and Rapid Transit, 224, $375-382$

19. Li M.X.D., Berggren E.G., Berg M., 2009, Assessment of vertical track geometry quality based on simulations of dynamic track-vehicle interaction, Journal of Rail and Rapid Transit, 223, 131-139

20. LiAng B., Zhu D., 2001, Dynamic analysis of the vehicle-subgrade model of a vertical coupled system, Journal of Sound and Vibration, 245, 79-92

21. Okada K., Ghataora G.S., 2002, Use of cyclic penetration test to estimate the stiffness of railway subgrade, NDT\&E International, 35, 65-74

22. Smutny J., 2004, Measurement and analysis of dynamic and acoustic parameters of rail fastening, NDT\&E International, 37, 119-129

23. Wu T.X., Thompson D.J., 2004, The effects of track nonlinearity on wheel/rail impact, Journal of Rail and Rapid Transit, 218, 1, 1-15

Manuscript received February 7, 2015; accepted for print August 12, 2016 